\title{
Charting Ecosystems of Complex Phenomena: The Precision Medicine Case
}

\author{
Rodolfo Wadovski*, Roberto Nogueira and Paula Chimenti \\ The COPPEAD Graduate Business School, Federal University of Rio de Janeiro (UFRJ), Brazil
}

Received: 制: September 07, 2018; Published: 制 September 20, 2018

*Corresponding author: Rodolfo Wadovski, The COPPEAD Graduate Business School, Federal University of Rio de Janeiro (UFRJ), Rua

Paschoal Lemme, 355, Cidade Universitária, Rio de Janeiro-RJ, Brazil

\begin{abstract}
This article proposes a structured method to map the main elements of complex phenomena. We chose Precision Medicine as the context for this study due to its novelty, exponential evolution, complexity, and potential impact on our future. The method proposed faces the problem that a subjective process of acquiring knowledge and building a common framework might be biased. The solution is achieved by an original way of combining systematic literature review, content analysis, and ecosystem approach. The method proposed also offers an innovative way to include factors and connect them to actors in an ecosystem approach. We present a four-phase method that ends with a double-layer diagram with actors and factors. It serves as a reference ground for discussions that are relevant for academic research and practitioner strategy development. Our findings in the Precision Medicine context suggest that this method could be used for other complex phenomena as well.
\end{abstract}

Keywords: Precision Medicine; Complex Phenomena; Systematic Literature Review; Content Analysis; Business Ecosystem; Structured Method

\section{Introduction}

During the last decades, business strategy studies were largely based on industrial age economics, such as value chain and industry analysis as those offered by Michael Porter (1980), on competition within industrial sectors [1-3]. However, the rapid technological innovations of the last decades have strongly impacted the business environment with the digitization phenomenon deeply transforming the way that a business is understood and managed. In today's information age, value chain analysis is not enough to fully understand the complex web of relationships among organizations and industries $[2,4]$.

A common definition of industry brings the idea of a broad business activity that can be isolated from others or is related to a specific field, country or region. Normally, a single industry is termed after its main product or service, such as retail, entertainment, education, and auto industry. From this standard, the Tesla Inc (formerly Tesla Motors) might be classified as an auto company. Nevertheless, its footprint comprehends several industries: automobile, distributed energy generation and storage, solar panels, and driverless cars.

Recent history shows that companies with narrow industry vision were surpassed by others that got comprehensive multiindustry perspectives. Xerox, with its Palo Alto Research Center created multi-billion-dollar businesses but did not capture the value created - Personal Computers, Local Area Networking,
Graphic User Interfaces, Object Oriented Programming are some of the inventions that were later brought to the market by other companies - 3Com, Apple Computer, Microsoft, among others. The narrow focus on the copier industry prevented Xerox to lead the most important industries of the late XX century [5]. Kodak has fallen similar trap. An employee from the company invented the digital photography but the company was blindsided at its industry, which, from Kodak viewpoint had nothing to do with "digital" [6]. IBM saw itself as a hardware company and unadvisedly allowed Microsoft dominates the software market [7]. Nokia was once the largest mobile phone company and have not seen Apple building a complex platform around the iPhone [8].

This change has not gone unnoticed by the scientific literature. It is not new that the value chain model should be complemented by a broader and systemic perspective. This warning has been present since the end of the last century [1,3,4,9-13]. Economic phenomena studies in information economy highlight the importance of a broad vision to substantiate comprehensive analyses and strategic planning [1,14-17]. Although in the early years of this century the ecosystem perspective was not given much attention compared to the traditional view [2], its use has been increasing since 2004, indicating the relevance of this perspective. In the daily life of consulting firms and classrooms, ecosystem analysis arrived to offer a comprehensive view of the contemporary business environment. There are also articles that propose a specific method to analyze 
ecosystem charts [18]. However, we still lack a fundamental piece of that kind of broad map: a systematic method to chart a business ecosystem from the available data [19]. The design of this initial graph is still done subjectively and does not favor replicability: what are the criteria to select the actors of an ecosystem and the links among actors? How can we follow up the phenomenon's ecosystem evolution if we don't have a reliable way to build it? Surprisingly, the process of charting an ecosystem is still carried out in a nonsystematic way.

The consequence of this is a possibly biased chart, especially when researchers use abundant references. While technology development has altered the business environment, it has also shaped a revolution in data availability and made it more difficult to adopt sound research practices. We tend to stick to familiar theories or paradigms, ignoring those that do not fit our preexisting inclinations. This avalanche of data, still relatively new to science, certainly contributes positively to research, but there are risks of biases if it is not carefully used. Overcoming this difficulty could be facilitated by developing appropriate methods to deal with the current complexity [20,21]. According to Buchanan and Bryman [22], the trend in the field of organizational research incorporates "widening of boundaries, adoption of a range of orientations (epistemologies), and methodological innovation".

Considering the absence of a reliable process to chart a comprehensive space of phenomena in the information age, this article proposes a method for charting business ecosystems, identifying and charting its actors and factors, as well as the interactions among them. We do so integrating tools into a rigorous and replicable method for complex phenomenon charting. It starts with a systematic literature review followed by content analysis. The third and fourth phases produce business ecosystem charts represented by a double-layer diagram with actors, factors, and their interactions. The context chosen for this first application is the Precision Medicine - a field of novelty, evolution, complexity, and potential impact in our futures.

The National Institutes of Health (NIH) of the United States defines Precision Medicine (PM) as "an emerging approach for disease treatment and prevention that considers individual variability in genes, environment, and lifestyle for each person" [23]. Because of technological advances, particularly in genetics and sensor interconnection, digitization increasingly influences health-related business models. Stakeholders from a wide range of industries collaborate in a complex network to seek growth and sell their healthcare services and products [2]. Precision Medicine is an emergent and complex phenomenon that encompasses several industries, has the potential to impact both private and public organizations as well as citizens worldwide but surprisingly has not yet been studied from an ecosystem perspective. Those are the main reasons for our choice.

We expect that this rigorous method of ecosystem charting serves for reaching a common representation of complex phenomenon. The wide visualization provided by the double-layer diagram potentially unveils research opportunities for academics, help practitioners with strategy development and can serve as a reference to track the phenomenon evolution.

\section{Healthcare and Precision Medicine}

Companies that operate with anything related to health should widen their vision on what was once a "health care industry". Health is a huge and growing market, with revenues of USD 7 trillion in 2015 [24], and according to the World Economic Forum "global health care is marked by growing concern over its sustainability. In particular, costs are growing at roughly double the rate of growth in gross domestic product" [25]. Adding to these problems technological aspects like the digitization of genetic data and the ubiquity of mobile devices, potentially allowing individuals control their data, it is possible to infer the whole system is on the verge of disruption. Combining data health digitization, revenues opportunities and cost growth, health care is very attractive for tech companies. What are the industries of Berkshire Hathaway, JP Morgan, and Amazon? In early 2018, they joined forces to offer health care services. The fast development of biotechnology, genetics, computing tools, and the exponential reduction in genotyping costs are the basis of what has come to be known as Precision Medicine (PM) [26-39]. PM is already an important topic in public and private health care debates with clear importance in the future. It presents a huge potential for the improvement in diseases' diagnostics, treatment and prevention [27,40-45].

Although the comprehensive approach of PM is already a reality in some cases, it is still in an embryonic stage and faces challenges at various levels [31,32,36,41-43]. PM's direct medical challenges are related to the complexity of life itself. Science is still in the beginning of understanding the relationship between genes and diseases. There is still no conclusive evidence of clinical utility for most parts of the genomic information. Moreover, due to the nearubiquitous presence of digital data, PM has to deal with interrelated fields, particularly information technology (IT) and computer science. Paradoxically, the increasing amount of genetic data is also a challenge as it makes the access, management, interpretation, and security of this data harder. Health care research requires a multidisciplinary view and the integration of knowledge coming from different fields [32,33,37,44,46,47].

In a higher-level perspective, there is a wide range of stakeholders and forces related to PM $[33,48]$. As in other economic phenomena where businesses are impacted by rapid technological innovation and there is interdependence among elements from different industries $[15,16,49,50]$, PM should be studied from a multiple industry perspective especially due to the complexities and implications of genetic research and treatment. Any analysis of PM should consider actors and factors outside the traditional medical industry such as educational institutes, IT companies, international collaboration, ethics, and privacy.

One example is the "Precision Medicine Initiative (PMI)" headed by public and private organizations in the US - National Institute of Health, universities, research centers, foundations (Bill and Melinda Gates), and corporations (Google, GE, and Intel). It deals with health, ethics, privacy, and security of individual information (PMI, 2015). 
Dr. George Church, a genomic scientist, founded Nebula, a company that uses blockchain to enable individuals to sell the access to their data to other organizations. There are other companies with a similar business model, such as LunaDNA, that will use "LunaCoins" as a way of payment to access genomic information. EncrypGen, Insilico, and Zenome have comparable models [51].

The diversity and complexity of this new reality bring a myriad of aspects that should be considered in an integrated way to have an all-encompassing understanding of PM. Nevertheless, scientific works have basically studied fragmented pieces of PM. Each article focuses on an important segment of the phenomenon separately: personalized health care, diseases, drugs, pharmacogenomics, drug printing technologies, decision making processes, computational biology, big data for health, therapy trials, health data cooperation, privacy, biobanks economic sustainability, patient issues, among many others. The scientific literature on PM has not yet presented a way to visualize the phenomenon from a macro standpoint. In addition to the literature reviewed, we have also observed that Precision Medicine is widely mentioned in seminars and discussions on genetic evolutions and the impact of new technologies on healthcare. But again, this happens in a fragmented way and there is no common ground for discussing the phenomenon at the ecosystem level. According to Miller and Van de Ven [52], it is like science has been studying trees and not the forest. So, the need for a broader perspective has already been realized. Aronson and Rehm [41] suggest that there is a PM ecosystem under development: "this ecosystem is beginning to link clinicians, laboratories, research enterprises, and clinical-information-system developers together in new ways".

There is an expectation that the consolidation of this ecosystem will facilitate the development of PM. An ecosystem perspective facilitates complexity understanding and building strategies $[53,54]$. This understanding transcends the usual practice of single industry analysis and goes beyond their boundaries to include other industries [16] as well as all sides of economic relations encompassing supply and demand perspectives $[15,50]$. The benefit of the ecosystem perspective rests on its capacity to depict a phenomenon's by highlighting the main actors and their relationships. The visualization provides a broad understanding, insights for designing and executing strategies, and a common basis for communication among people [14-17,19,55-59].

Despite the rich literature on ecosystems, there is yet no guideline on how to establish its boundaries. Ecosystems are supposed to be broad, but they also need to be viable, readable, and practical. If the idea is to be as broad as possible, when should we stop so that the ecosystem is viable and usable without losing its relevance? Furthermore, how should the factors in an ecosystem be handled? Considering the analogy of biology, actors would be the living species and the factors would be the conditions of the environment such as sunlight, temperature, wind, air humidity, etc. When reviewing the literature, factors will inevitably appear as important foundations for research. So, in an ecosystem analysis, it would also be important to consider them. Until now, the literature did not present a way to link both ecosystems' actors and factors in a comprehensible graph.

\section{The Method Proposed}

Our proposition is that this can be done by mapping actors and factors in a broad and systematic way, producing an ecosystem chart Precision Medicine field with the most relevant actors, connections and factors that have already been studied in the literature. The following methodological description aims to provide transparency and replicability [60] of our work. We prescribe four phases:
a) 1st Phase: Systematic Literature Review
i. 1 st Step - Search for key terms
ii. 2nd Step - Apply broad criteria to article selection
iii. 3rd Step - Sort articles by citation
iv. 4th Step - Skim read the articles, applying specific criteria to produce a final list of relevant articles
b) 2nd Phase: Content Analysis

i. 1st Step - Data collection: full reading of the previously listed articles, identifying actors and factors

ii. 2nd Step - Coding: Compile the actors and factors into a double roster

iii. 3rd Step - Interpretation: mark factors that strongly relates to each actor (experts included in the discussion)

c) 3rd Phase: Ecosystem Charting Process

i. 1st Step - Build successive ecosystems based on common factors between actors

ii. 2nd Step - Produce charts for several contrast levels and select the optimum threshold for its links

d) 4th Phase: Produce the final Double-Layer Diagram of the ecosystem

Each phase is described with its main results in the following sections.

\section{a) $1^{\text {st }}$ Phase: Systematic Literature Review}

In order "to identify a wide range of theoretically related constructs for possible inclusion in a discriminant validity analysis" [61], a systematic literature review following the guidelines proposed by Jesson [62] was performed. "Systematic reviews provide a systematic, transparent means for gathering, synthesizing and appraising the findings of studies on a particular topic or question. The aim is to minimize the bias associated with single studies and nonsystematic reviews" [62].

We searched for the term "Precision Medicine" in four multidisciplinary databases. The search was conducted on October 25th, 2016. The returns were: SCOPUS: 3156; Web of Science: 1620; PROQUEST: 8852; and EBSCO: 909; totalizing 14537. The next step was to apply inclusion and exclusion criteria over the first 
round of the search [62]. We decided to analyze only peer review journals and articles in English. The numbers were: SCOPUS: 1285; Web of Science: 671; PROQUEST: 226; and EBSCO: 193; totalizing 2375. Continuing the use of inclusion and exclusion criteria, we consolidated the metadata of 2375 articles to perform a comparative analysis of the four databases. Many articles appeared in more than one database (when a duplicate was found, we kept the SCOPUS one for reasons that will be evident soon). Other articles were removed because some necessary fields were missing such as the abstract. The final numbers after removing duplicates and articles with missing fields were: SCOPUS: 1179 (72.2\%); Web of Science: 244 (15\%); PROQUEST: 108 (6.6\%); and EBSCO: 102 (6.2\%); totalizing $1633(100 \%)$. Considering that SCOPUS presented a significant superiority in the number of articles (72.2\%) and to facilitate and standardize the analysis of the articles, we decided to use only this database. Furthermore, Scopus is the only one that clearly has "cited by" (number of citations of the article) as part of its metadata. This property, which is an indicative of relevance, allows sorting articles by a practical criterion. Moreover, SCOPUS is multidisciplinary and considered "the world's largest abstract and citation database of peer-reviewed research literature" [63]. Then the 1,179 articles were sorted by citations using 5 citations as the threshold criteria - 207 were selected. We read their title and abstracts identifying those with multidisciplinary scope - 53 were kept in the workflow. They were thoroughly read multidisciplinary. We ended up with 45 articles - our final base (Appendix I). On February $1^{\text {st }}, 2018$ we replicated the search and found no additional articles to be included. Figure 1 shows the steps of this first phase.

\begin{tabular}{|c|c|c|}
14535 & Results of searching the term "Precision Medicine" on four databases \\
2375 & Articles after removing duplicates and missing fields \\
1179 & Articles after restricting to scopus database \\
207 & Articles with more than 5 citations - title and abstract were analyzed \\
53 & Total of articles with multidisciplinary scope - those articles were studied deeply \\
45 & Final list of articles that serves as base for identifying the elements of the ecosystem
\end{tabular}

Figure 1: "Precision Medicine" keyword search mapping process.

\section{b) $2^{\text {nd }}$ Phase: Content Analysis}

Content analysis was based on the "logic of discovery" as it is not yet possible to check or test inferences. Our reasoning was an abduction, which "begins by recognizing an anomaly or breakdown in our understanding of the world and proceeds to create a hypothetical inference that dissolves the anomaly by providing a coherent resolution to the problem" [64]. The goal was to conceive a model for the Precision Medicine ecosystem. In order to allow room for creativity and for pursuing a more generic picture of the main characteristics of the phenomenon [64], we re-connected the ideas from the 45 articles. The steps were data collection, coding, and interpretation [65-67]. In the first step, we conducted the data collection by reading the 45 articles seeking for "actors" and "factors" related to the Precision Medicine ecosystem. We considered an "actor" as any active participant of the ecosystem and a "factor" any element that refers to those actors.

The following step was to classify them into categories to create a more parsimonious list. That was based on concepts and semantic similarities found in the literature $[61,64,68]$. From a group of similar words to a broader construct, we inductively interpreted the raw data to arrive at a more general meaning. That aggregation elevated the level of abstraction to form broader constructs [69]. So, from the 45 articles we identified 278 terms associated to actors and 1,734 to factors that were later classified into 12 categories of actors (Appendix II) and 12 of factors (Appendix III).

The third step of the second phase was the establishment of associations among actors and factors, that is, for each actor what factors impact them the most. In this step, we engaged other academics and practitioners in the debate to incorporate expert knowledge into our interpretations [61]. A matrix relating actors to factors was produced (Table I).

\section{c) $\quad 3^{\text {rd }}$ Phase: Ecosystem Charting Process}

The goal was to build the ecosystem following a structured and replicable method [60]. The criterion for relating two actors was the existence of common factors. If we consider a small number of common factors as being sufficient to set a relationship, most likely all actors will be connected. On the other hand, if we demand too many factors, few links would be set. There is a clear trade-off here and our goal is to capture most of the information while trying to avoid the noise from spurious relations.

In accordance with Bastian, Heymann, and Jacomy [70] and Khokhar [71], Gephi software was used for charting, taking the actors vs. factors matrix as the starting point. We ran the graph twelve times while controlling the threshold linkage, starting from a single citation and going all the way up to 12 . For each graph, the 
software computed its density - ranging from 0.985 (most actors linked) with the lowest threshold down to 0 for the 12 -factor requirement (Figure 2).

As our goal is to display the best information possible [55], we created an index based on density (Figure 2) and number of common factors (Table 1) and looked for its maximum (Figure 3) and selected the 7 common factors solution. It is interesting to note ("Factors in common: 7", in Figure 1) that there is one actor (Funders) disconnected when we use this level of requirement. It does not mean that Funders do not belong to the ecosystem, it only indicates that this actor has weaker ties compared to other actors.

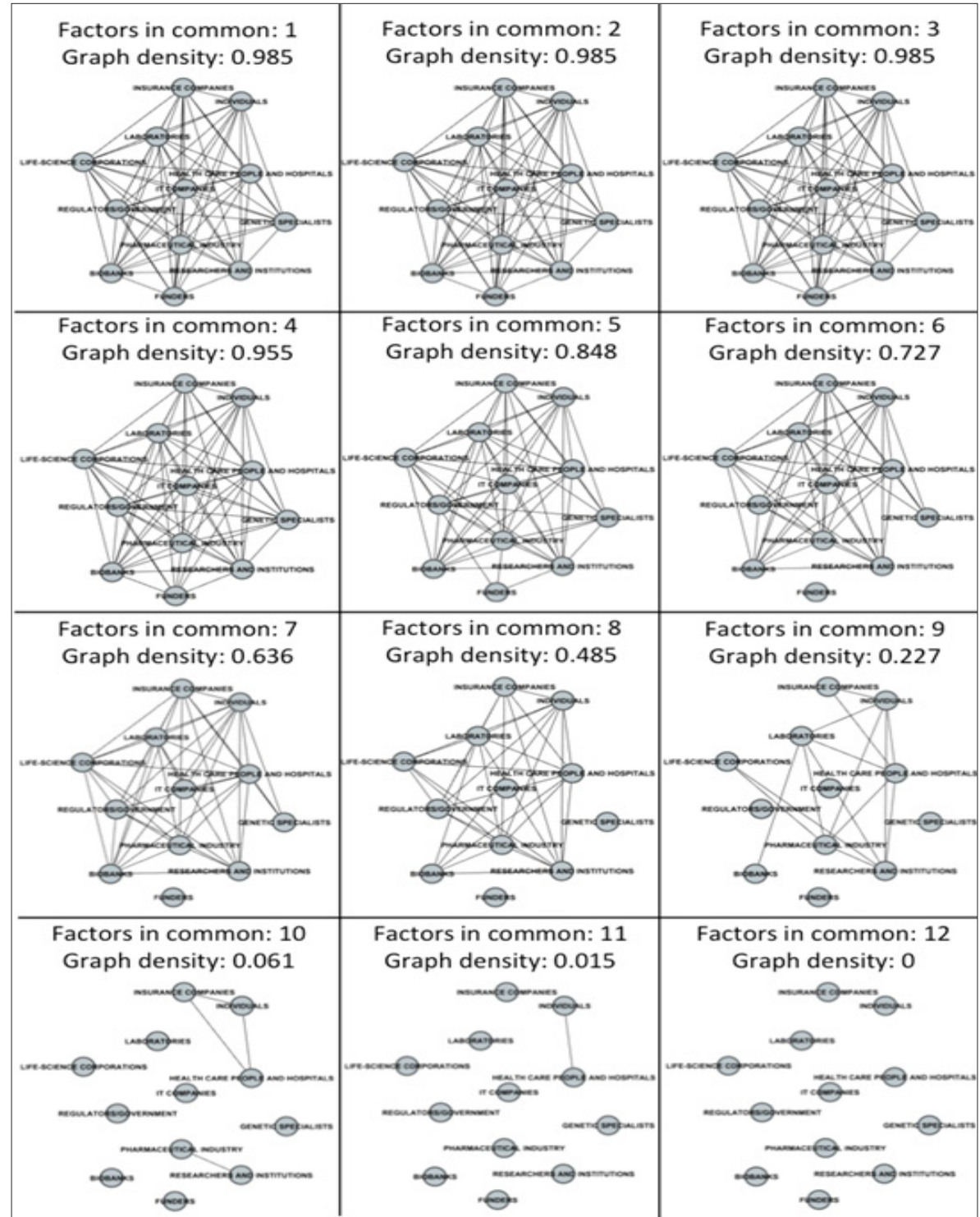

Figure 2: Ecosystems according to the number of common factors.

Table 1: Associations between actors and factors.

\begin{tabular}{|c|c|c|c|c|c|c|c|c|c|c|c|c|}
\hline $\begin{array}{c}\text { FACTORS } \rightarrow \\
\text { ACTORS } \downarrow\end{array}$ & Treatment & Data & Testing & Research & Technologies & Drugs & Individuality & Heterogeneity & $\begin{array}{l}\text { Funding } \\
\text { and Costs }\end{array}$ & $\begin{array}{c}\text { Ethical- } \\
\text { Social }\end{array}$ & Regulation & $\begin{array}{l}\text { Privacy } \\
\text { and } \\
\text { Security }\end{array}$ \\
\hline Individuals & $\mathrm{x}$ & $\mathrm{x}$ & $\mathrm{x}$ & & $\mathrm{x}$ & $\mathrm{x}$ & $\mathrm{x}$ & $\mathrm{x}$ & $\mathrm{x}$ & $\mathrm{x}$ & $\mathrm{x}$ & $\mathrm{x}$ \\
\hline $\begin{array}{l}\text { Health Care } \\
\text { People and } \\
\text { Hospitals }\end{array}$ & $\mathrm{x}$ & $\mathrm{x}$ & $\mathrm{x}$ & & $\mathrm{x}$ & $\mathrm{x}$ & $\mathrm{x}$ & $\mathrm{x}$ & $\mathrm{x}$ & $\mathrm{x}$ & $\mathrm{x}$ & $\mathrm{x}$ \\
\hline $\begin{array}{c}\text { Genetic } \\
\text { Specialists }\end{array}$ & $\mathrm{x}$ & $\mathrm{x}$ & $\mathrm{x}$ & & & & $\mathrm{x}$ & $\mathrm{x}$ & & $\mathrm{x}$ & & $\mathrm{x}$ \\
\hline
\end{tabular}




\begin{tabular}{|c|c|c|c|c|c|c|c|c|c|c|c|c|}
\hline $\begin{array}{l}\text { Researchers } \\
\text { and Research } \\
\text { Institutions }\end{array}$ & & $\mathrm{x}$ & $\mathrm{x}$ & $\mathrm{x}$ & $\mathrm{x}$ & $\mathrm{x}$ & & $\mathrm{x}$ & $\mathrm{x}$ & $\mathrm{x}$ & $\mathrm{x}$ & $\mathrm{x}$ \\
\hline $\begin{array}{l}\text { Regulators/ } \\
\text { Government }\end{array}$ & & & $\mathrm{x}$ & $\mathrm{x}$ & & $\mathrm{x}$ & $\mathrm{x}$ & $\mathrm{x}$ & $\mathrm{x}$ & $\mathrm{x}$ & $\mathrm{x}$ & $\mathrm{x}$ \\
\hline Laboratories & & $\mathrm{x}$ & $\mathrm{x}$ & $\mathrm{x}$ & $\mathrm{x}$ & & $\mathrm{x}$ & $\mathrm{x}$ & $\mathrm{x}$ & $\mathrm{x}$ & $\mathrm{x}$ & $\mathrm{x}$ \\
\hline $\begin{array}{l}\text { Life-Science } \\
\text { Corporations }\end{array}$ & & $\mathrm{x}$ & $\mathrm{x}$ & $\mathrm{x}$ & $\mathrm{x}$ & $\mathrm{x}$ & & & $\mathrm{x}$ & $\mathrm{x}$ & $\mathrm{x}$ & $\mathrm{x}$ \\
\hline $\begin{array}{c}\text { Pharmaceutical } \\
\text { Industry }\end{array}$ & & $\mathrm{x}$ & $\mathrm{x}$ & $\mathrm{x}$ & $\mathrm{x}$ & $\mathrm{x}$ & & $\mathrm{x}$ & $\mathrm{x}$ & $\mathrm{x}$ & $\mathrm{x}$ & $\mathrm{x}$ \\
\hline IT Companies & & $\mathrm{x}$ & $\mathrm{x}$ & & $\mathrm{x}$ & & $\mathrm{x}$ & & $\mathrm{x}$ & & $\mathrm{x}$ & $\mathrm{x}$ \\
\hline $\begin{array}{c}\text { Insurance } \\
\text { Companies }\end{array}$ & $\mathrm{x}$ & $\mathrm{x}$ & $\mathrm{x}$ & & & $\mathrm{x}$ & $\mathrm{x}$ & $\mathrm{x}$ & $\mathrm{x}$ & $\mathrm{x}$ & $\mathrm{x}$ & $\mathrm{x}$ \\
\hline Funders & & & & $\mathrm{x}$ & $\mathrm{x}$ & $\mathrm{x}$ & & & $\mathrm{x}$ & & $\mathrm{x}$ & \\
\hline Biobanks & & $\mathrm{x}$ & & $\mathrm{x}$ & $\mathrm{x}$ & & $\mathrm{x}$ & $\mathrm{x}$ & $\mathrm{x}$ & $\mathrm{x}$ & $\mathrm{x}$ & $\mathrm{x}$ \\
\hline
\end{tabular}

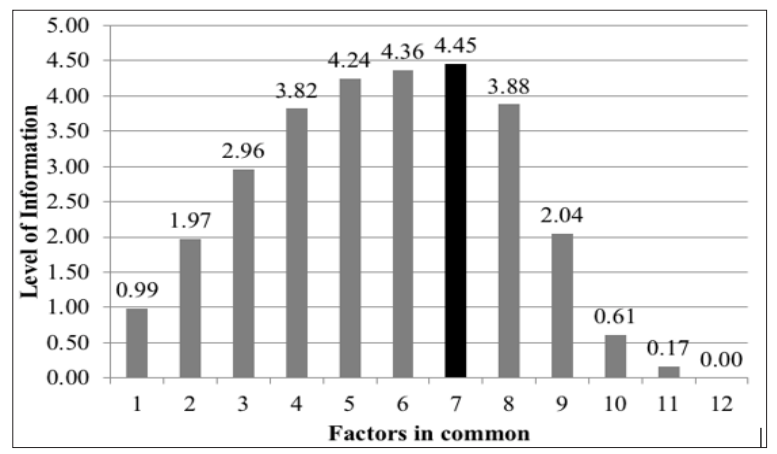

Figure 3: Quantity and quality equilibrium in the ecosystems' series.

\section{d) $\quad 4^{\text {th }}$ Phase: Double-Layer Diagram}

Finally, in the fourth phase we added the factors to the ecosystem chosen to obtain the double-layer diagram. Figure 4 shows the actors (red) and the factors (green) in two layers. One layer comes from a spatial organization of the ecosystem chosen and shows the direct relationship (red) between actors. The other layer shows the associations (green) between actors (Appendix II) and factors(Appendix III).

According to Agar [64] "whereas the process of abduction begins with recognizing a breakdown or anomaly, it ends with a coherent resolution". We believe this represents the Precision Medicine business ecosystem enriched with its factors and associations. The coherence of this resolution is supported by a systematic review of a heterogeneous set of scientific works with different approaches to Precision Medicine. The comprehension extract from that group of articles abstracts idiosyncratic details and connects broad knowledge to form a whole with meaning greater than the sum of its parts. This visualization is a versatile map that unveils the big picture of the Precision Medicine phenomenon considering a wide spectrum of stakeholders, providing insights for various sorts of analyses. By looking at the double-layer diagram, it is possible to identify which factors tend to impact more intensely each pair of relation. It is also possible to analyze actors' interdependence by looking at the common factors.

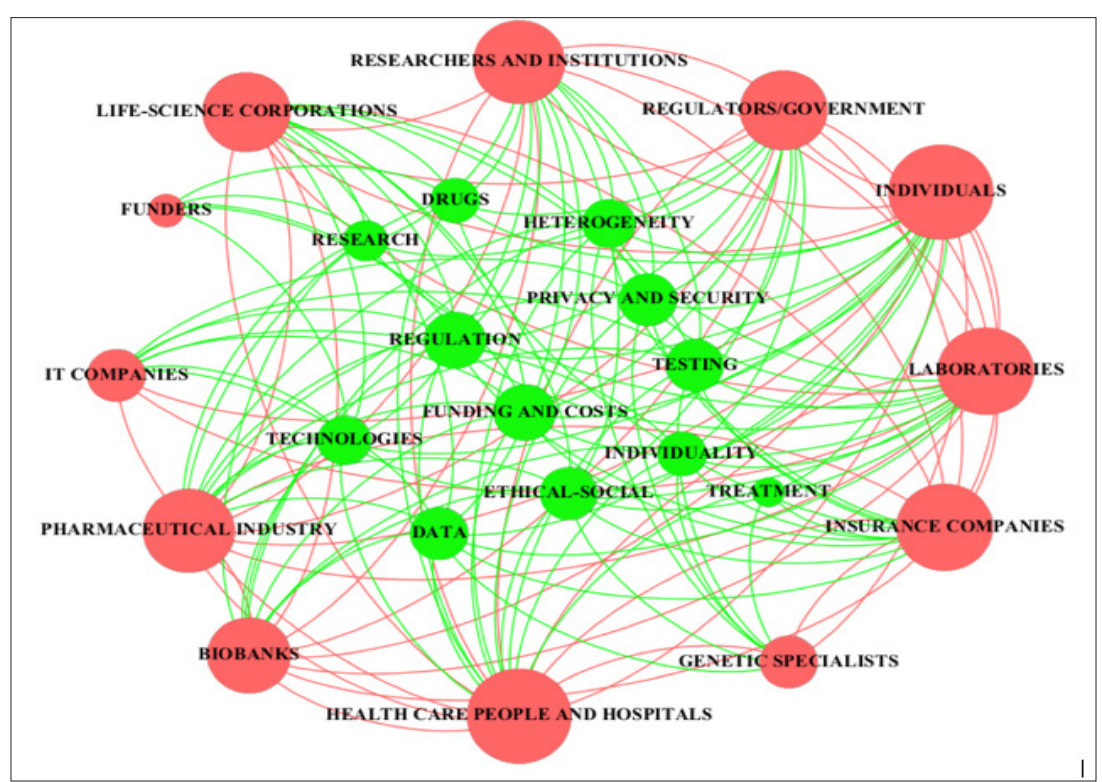

Figure 4: Precision Medicine "double-layer diagram". 
Regarding complex phenomena, particularly PM, this kind of comprehensive view is vital. According to WEF [25] "The fundamental principle of value in healthcare is, first, to align industry stakeholders around the shared objective of improving health outcomes delivered to patients at a given cost." Poorly coordinated care causes many of the 250,000 deaths related to medical error in America [72]. From the digital startup's point of view, one key aspect is the integration of health ecosystem, because they need data from hospitals or physician offices [73].

In order to align, coordinate or integrate the stakeholders of a phenomenon, it is first necessary to identify precisely who they are. We believe that we achieve this purpose in the case of PM by using the method proposed. The double-layer diagram illuminates the diversity of actors and factors of PM. It also presents a vision that goes beyond traditional value chains, which concentrate their analysis within a given industry, sometimes exaggerate the relative importance of competitors and suppliers, and do not emphasize the importance of partners, complementors, and cooperation, as well as do not examine the factors. The analysis of the PM ecosystem is a subsequent work, which can now be performed on a solid basis.

This double-layer diagram is a picture of the moment, but an ecosystem's structure is in constant change. Actors co-evolve in accordance with unpredictable new desires and circumstances. There is no general rule to predict which innovations will emerge. Its dynamic nature implies that longitudinal studies are useful to follow up its progression $[15,50,56,58,74,75]$. So, the method proposed is also valuable to track the evolution of phenomena in a consistent way.

In this article, we arrived at the double-layer diagram of the Precision Medicine phenomenon by following the steps established by the method proposed, through careful work of exploration and interpretation of the interactions and interdependencies of the various elements of the phenomenon. This systematic process, according to Dougherty [76], makes it possible to generalize to other complex phenomena [77-104].

\section{Conclusion}

The purpose of this article is to propose a method for charting a complex phenomenon, its actors and factors, as well as the interactions among them. As a case example, our goal was understanding the Precision Medicine phenomenon from a broad and comprehensive perspective. From a generic initial search for the term "precision medicine", then using pre-established criteria (i.e. peer reviewed, English language, multidisciplinary, and more than 5 citations), we narrow the number of articles from 14,537 to 45. From this final listing, we conduct a content analysis that has led us to 12 categories of actors and factors. An expert panel was used to check and complement our cross-tabulation of actors vs. factors and a final table was produced controlled by the threshold level, which was loaded on Gephi software to produce the ecosystem charts. By balancing data (links) and relevance (number of common factors), a final ecosystem chart was produced, thus maximizing the information vs. noise ratio. A second layer was imposed in a final stage, bringing the factor dimension to the graph.
This process allows a research group to perform a comprehensive literature review and represents the information needed for a broad strategic analysis from an ecosystem perspective encompassing several industries. Since dealing with emerging technologies such as the ones involved in Precision Medicine requires broad perspective for planning, execution, and control, we believe that this method can help both academics and practitioners in their journeys to understand a new and complex phenomenon.

We believe that using a systematic literature review as the first phase of the method proposed helped to reduce the bias about the state-of-the-art knowledge concerning Precision Medicine. It also delineates the boundaries of the phenomenon. Another achievement was to methodically include the factors in the ecosystem design. At the end of the process, it was possible to highlight the key actors, factors, and their interaction in the Precision Medicine ecosystem, reaching the forest view instead of only a handful of trees. We believe that the method could be used for other phenomena as well.

There are several limitations and opportunities for future researches. We decided to use only peer-review articles. The advantage is to remain inside the scientific literature. However, as new technological phenomenon evolves fast, most likely there are important innovations that have not yet been published. In the method, the associations between actors and factors may bring some controversy due to the subjective nature of the expert panel. A future research could improve the way to set those associations. Regarding Precision Medicine, as each actor has different peculiarities and demands, future researches could deepen the analysis, grounding smaller scale examination on a plausible macro perspective. Also, the wide perspective offered by the doublelayer diagram can provide insights for scenario planning. Lastly, longitudinal researches can follow the evolution expected in the Precision Medicine ecosystem.

\section{References}

1. Gossain Sanjiv, Kandiah Gajen (1998) Reinventing value: The new business ecosystem. Strategy \& Leadership 26(5): 28-33.

2. Pellikka Jarkko, Timo Ali-Vehmas (2016) Managing Innovation Ecosystems to Create and Capture Value in ICT Industries. Technology Innovation Management Review 6(10).

3. Pil Frits, Holweg Matthias (2006) Evolving from Value Chain to Value Grid. MITS loan Management Review.

4. Shapiro Carl, Varian Hal R (1999) Information Rules. Boston: HBSP.

5. Hiltzik Michael A (2000) Dealers of Lightning: Xerox PARC and the Dawn of the Computer Age. HarperBusiness, New York, USA.

6. Ismail Salim, Malone MS, van Geest Y (2014) Exponential Organizations. Diversion Books.

7. Carroll Paul (1994) Big Blues: The Unmaking of IBM. Three Rivers Press.

8. (2018) Nokia: Our History.

9. Allee Verna (2000) Reconfiguring the value network. Journal of Business strategy 21(4): 36-39.

10. Frosch Robert A, Nicholas E Gallopoulos (1989) Strategies for manufacturing. Scientific American 261(3): 144-152.

11. Meyer Alan D, Vibha Gaba, Kenneth A. Colwell (2005) Organizing far from equilibrium: Nonlinear change in organizational fields. Organization Science 16(5): 456-473. 
12. Moore JF (1993) Predators and prey: The new ecology of competition Harvard Business Review 71: 75-83.

13. Normann Richard, Rafael Ramirez (1993) From value chain to value constellation: Designing interactive strategy. Harvard business review 71(4): $65-77$

14. Adner Ron (2006) Match Your Innovation Strategy to Your Innovation Ecosystem. Harvard Business Review 84(4): 98.

15. Autio E, Thomas LDW (2014) Innovation ecosystems: Implications for innovation management. In: M Dodgson, DM Gann, N Phillips (Eds.) Oxford Handbook of Innovation Management, Oxford, UK: Oxford University Press, pp. 204-228.

16. Iansiti M, Levien R (2004) Strategy as Ecology. Harvard Business Review 82: 68-78.

17. Peltoniemi Mirva, Elisa Vuori (2004) Business Ecosystem as the New Approach to Complex Adaptive Business Environments. In Proceedings of eBusiness Research Forum pp. 267-281.

18. Battistella Cinzia (2013) Methodology of business ecosystems network analysis: A case study in Telecom Italia Future Centre. Technological Forecasting and Social Change 80(6): 1194-1210.

19. Tsujimoto Masaharu (2017) A review of the ecosystem concept-Towards coherent ecosystem design. Technological Forecasting and Social Change.

20. Davis Gerald F (2010) Do theories of organizations progress? Organizational Research Methods 13(4): 690-709.

21. Wenzel Ramon, Niels Van Quaquebeke (2017) The Double-Edged Sword of Big Data in Organizational and Management Research: A Review of Opportunities and Risks. Organizational Research Methods 21(3).

22. Buchanan David A, Alan Bryman (2007) Contextualizing methods choice in organizational research. Organizational Research Methods 10(3): 483-501.

23. National Institutes of Health (NIH) (2017) What Is Precision Medicine? Genetics Home Reference.

24. The Economist (2018b) Tech giants go to med school Apple and Amazon's moves in health signal a coming transformation. The Economist.

25. WEF (2017) Value in Healthcare: Laying the Foundation for Health System Transformation. World Economic Forum in collaboration with The Boston Consulting Group (BCG).

26. Bailey Ann M, Yong Mao, Jia Zeng, Vijaykumar Holla, Amber Johnson, et al. (2014) Implementation of Biomarker-Driven Cancer Therapy: Existing Tools and Remaining Gaps. Discovery Medicine 17(92): 101114.

27. Gaziano John Michael, John Concato, Mary Brophy, Louis Fiore, Saiju Pyarajan, et al. (2016) Million Veteran Program: A Mega-Biobank to Study Genetic Influences on Health and Disease. Journal of Clinical Epidemiology 70: 214-223.

28. Guo Lining, Michael V Milburn, John A Ryals, Shaun C Lonergan, Matthew W Mitchell, et al. (2015) Plasma Metabolomic Profiles Enhance Precision Medicine for Volunteers of Normal Health. Proceedings of the National Academy of Sciences 112(35): E4901-E4910.

29. Hafen E, D Kossmann, A Brand (2014) Health Data Cooperatives - Citizen Empowerment. Methods of Information in Medicine 53(2): 82-86.

30. Harrer S, SC Kim, C Schieber, S Kannam, N Gunn, et al. (2015) LabelFree Screening of Single Biomolecules through Resistive Pulse Sensing Technology for Precision Medicine Applications. Nanotechnology 26(18): 182502.

31. Kampourakis K, E Vayena, C Mitropoulou, RH van Schaik, DN Cooper, et al. (2014) Key Challenges for next-Generation Pharmacogenomics. Science \& Society EMBO Reports 15(5): 472-476.
32. Kensler TW, A Spira, JE Garber, E Szabo, JJ Lee, et al. (2016) Transforming Cancer Prevention through Precision Medicine and Immune-Oncology. Cancer Prevention Research 9(1): 2-10.

33. Lawler M, LL Siu, HL Rehm, SJ Chanock, G Alterovitz, et al. (2015) All the World's a Stage: Facilitating Discovery Science and Improved Cancer Care through the Global Alliance for Genomics and Health. Cancer Discovery 5(11): 1133-1136.

34. Schwaederle M, BA Parker, RB Schwab, PT Fanta, SG Boles, et al. (2013) Molecular Tumor Board: The University of California San Diego Moores Cancer Center Experience. The Oncologist 19(6): 631-636.

35. Stadler ZK, KA Schrader, J Vijai, ME Robson, K Offit (2014) Cancer Genomics and Inherited Risk. Journal of Clinical Oncology 32(7): 687698.

36. Weitzel Kristin W, Madeline Alexander, Barbara A Bernhardt, Neil Calman, David J Carey, et al. (2015) The IGNITE Network: A Model for Genomic Medicine Implementation and Research. BMC Medical Genomics 9: 1.

37. Yip Vlm, Db Hawcutt, M Pirmohamed (2015) Pharmacogenetic Markers of Drug Efficacy and Toxicity. Clinical Pharmacology \& Therapeutics 98(1): 61-70.

38. Yusuf Rafeek A, Deevakar Rogith, Shelly RA Hovick, Susan K Peterson, Allison M Burton-Chase, et al. (2015) Attitudes toward Molecular Testing for Personalized Cancer Therapy: Attitudes Toward Molecular Testing. Cancer 121(2): 243-250.

39. Zhao Y, E Polley, M Li, C Lih, A Palmisano, et al. (2015) GeneMed: An Informatics Hub for the Coordination of Next-Generation Sequencing Studies That Support Precision Oncology Clinical Trials. Cancer Informatics 14: 45-55.

40. Andreu-Perez Javier, Daniel R Leff, HMD Ip, Guang-Zhong Yang (2015) From Wearable Sensors to Smart Implants-Toward Pervasive and Personalized Healthcare. IEEE Transactions on Biomedical Engineering 62(12): 2750-2762.

41. Aronson Samuel J, Heidi L Rehm (2015) Building the Foundation for Genomics in Precision Medicine. Nature 526(7573): 336-342.

42. Auffray Charles, Timothy Caulfield, Julian L Griffin, Muin J Khoury, James R Lupski (2016) From Genomic Medicine to Precision Medicine: Highlights of 2015. Genome Medicine 8: 12.

43. Li Jiao, Si Zheng, Bin Chen, Atul J Butte, S Joshua Swamidass, et al. (2016) A Survey of Current Trends in Computational Drug Repositioning. Briefings in Bioinformatics 17(1): 2-12.

44. Vogt Henrik, Bjørn Hofmann, Linn Getz (2016) The New Holism: P4 Systems Medicine and the Medicalization of Health and Life Itself. Medicine, Health Care and Philosophy 19(2): 307-323.

45. Weitzel Jeffrey N, Kathleen R Blazer, Deborah J MacDonald, Julie O Culver, Kenneth Offit (2011) Genetics, Genomics, and Cancer Risk Assessment: State of the Art and Future Directions in the Era of Personalized Medicine. CA: A Cancer Journal for Clinicians 61(5): 327-359.

46. Maresso KC, Tsai KY, Brown PH, Szabo E, Lippman S, et al. (2015) Molecular cancer prevention: Current status and future directions. CA Cancer J Clin 65(5): 345-383.

47. Meyskens FL Jr, Mukhtar H, Rock CL, Cuzick J, Kensler TW, et al. (2015) Cancer prevention: Obstacles, challenges and the road ahead. J Nat Cancer Inst 108(2): djv309.

48. Godman Brian, Alexander E Finlayson, Parneet K Cheema, Eva ZebedinBrandl, Inaki Gutiérrez-Ibarluzea, et al. (2013) Personalizing Health Care: Feasibility and Future Implications. BMC Medicine 11(1): 179.

49. Day George S, Paul JH Schoemaker, Robert E Gunther (2004) Wharton on managing emerging technologies. John Wiley \& Sons. 
50. Metcalfe Stan, Ronnie Ramlogan (2008) Innovation Systems and the Competitive Process in Developing Economies. The Quarterly Review of Economics and Finance 48(2): 433-446.

51. Rogers Adam (2018) Solve Genomics with the Blockchain? Why the Hell Not, Wired.

52. Mille CC, AH Van de Ven (2015) Peer Review, Root Canals, and Other Amazing Life Events. Academy of Management Discoveries 1(2): 117 123.

53. Williamson PJ, De Meyer A (2012) Ecosystem advantage: How to Successfully Harness the Power of Partners. California Management Review 55(1): 24-46.

54. Wu Jie (2012) Technological collaboration in product innovation: The role of market competition and sectoral technological intensity. Research Policy 41(2): 489-496.

55. Basole Rahul C, Jürgen Karla (2011) On the Evolution of Mobile Platform Ecosystem Structure and Strategy. Business \& Information Systems Engineering 3(5): 313-322.

56. Iyer B, Lee CH, Venkatraman N (2006) Managing in a "Small World Ecosystem": Lessons from the software sector. California Management Review 48(3): 28-47.

57. Kaplan RS, Norton DP (2000) Having Trouble with Your Strategy? Then Map it. Harvard Business Review 78(5): 167-176.

58. Mercan Birol, D Goktas (2011) Components of Innovation Ecosystems: A Cross-Country Study. International Research Journal of Finance and Economics 76: 102-112.

59. Venkatraman N, Chi-Hyon Lee (2004) Preferential Linkage and Network Evolution: A Conceptual Model and Empirical Test in the US Video Game Sector. Academy of Management Journal 47(6): 876-892.

60. Pratt MG (2008) Fitting oval pegs into round holes: Tensions in evaluating and publishing qualitative research in top North American journals. Organizational Research Methods 11(3): 481-509.

61. Shaffer Jonathan A, David De Geest, Andrew Li (2016) Tackling the Problem of Construct Proliferation: A Guide to Assessing the Discriminant Validity of Conceptually Related Constructs. Organizational Research Methods 19(1): 80-110.

62. Jesson Jill, Lydia Matheson, Fiona M Lacey (2011) Doing Your Literature Review: Traditional and Systematic Techniques. Sage, UK.

63. Wikipedia (2017) List of academic databases and search engines.

64. Van de Ven AH (2007) Engaged scholarship: A guide for organizational and social research. Oxford University Press, New York, USA, p. 98.

65. Duriau Vincent J, Rhonda K Reger, Michael D Pfarrer (2007) A content analysis of the content analysis literature in organization studies: Research themes, data sources, and methodological refinements. Organizational research methods 10(1): 5-34.

66. Roberts Carl W (1997) Text Analysis for the Social Sciences: Methods for Drawing Statistical Inferences from Texts and Transcripts. LEA's Communication Series. Erlbaum, Mahwah NJ, USA, pp. 316.

67. Weber Robert P (1990) Basic Content Analysis. Series: Quantitative Applications in the Social Sciences. Newbury Park, California: Sage Publications.

68. Creswell JW (2003) Research design: Qualitative, quantitative and mixed methods approaches. ( $2^{\text {nd }}$ edn); Thousand Oaks: Sage.

69. Osigweh CAB (1989) Concept Fallibility in Organizational Science. Academy of Management Review 14(4): 579-594.

70. Bastian M, Heymann S, Jacomy M (2009) Gephi: An open source software for exploring and manipulating networks. International AAAI Conference on Weblogs and Social Media.

71. Khokhar Devangana (2015) Gephi Cookbook. Packt Publishing.
72. The Economist (2018a) Data and medicine: A revolution in health care is coming. The Economist.

73. Aziz Fahad (2018) Why Digital Health Startups Have Yet to Reach Unicorn Status, Forbes.

74. Basole Rahul C (2009) Visualization of Interfirm Relations in a Converging Mobile Ecosystem. Journal of Information Technology 24(2): 144-159.

75. Durst Susanne, Pirjo Ståhle (2013) Success Factors of Open Innovation-A Literature Review. International Journal of Business Research and Management 4(4): 111-131.

76. Dougherty D (2015) Reflecting on the reflective conversation. Organizational Research Methods, 18(4): 606-611.

77. Albert Monique, John Bartlett, Randal N Johnston, Brent Schacter, Peter Watson (2014) Biobank Bootstrapping: Is Biobank Sustainability Possible Through Cost Recovery? Biopreservation and Biobanking 12(6): 374-380.

78. Alomari Mustafa, Fatima H Mohamed, Abdul W Basit, Simon Gaisford (2015) Personalised Dosing: Printing a Dose of One's Own Medicine. International Journal of Pharmaceutics 494(2): 568-577.

79. Andreu-Perez Javier, Carmen CY Poon, Robert D Merrifield, Stephen TC Wong, Guang-Zhong Yang (2015) Big Data for Health. IEEE Journal of Biomedical and Health Informatics 19(4): 1193-1208.

80. Bodei Lisa, Anders Sundin, Mark Kidd, Vikas Prasad, Irvin M Modlin (2014) The Status of Neuroendocrine Tumor Imaging: From Darkness to Light? Neuroendocrinology 101(1): 1-17.

81. Bouchard Claude, Ligia M, Antunes-Correa, Euan A Ashley, Nina Franklin, et al. (2015) Personalized Preventive Medicine: Genetics and the Response to Regular Exercise in Preventive Interventions. Progress in Cardiovascular Diseases 57(4): 337-346.

82. Colvin Monica, Nancy K Sweitzer, Nancy M Albert, Rajan Krishnamani, Michael W Rich, et al. (2015) Heart Failure in Non-Caucasians, Women, and Older Adults: A White Paper on Special Populations from the Heart Failure Society of America Guideline Committee. Journal of Cardiac Failure 21(8): 674-693.

83. Costello James C, Laura M Heiser, Elisabeth Georgii, Mehmet Gönen, Michael P Menden, et al. (2014) A Community Effort to Assess and Improve Drug Sensitivity Prediction Algorithms. Nature Biotechnology 32(12): 1202-1212.

84. Donnelly Kyla Z, Tina C Foster, Rachel Thompson (2014) What Matters Most? The Content and Concordance of Patients' and Providers' Information Priorities for Contraceptive Decision Making. Contraception 90(3): 280-287.

85. Hansen J, R Iyengar (2013) Computation as the Mechanistic Bridge Between Precision Medicine and Systems Therapeutics. Clinical Pharmacology \& Therapeutics 93(1): 117-128.

86. Kaddurah-Daouk R, R Weinshilboum, Pharmacometabolomics Research Network (2015) Metabolomic Signatures for Drug Response Phenotypes: Pharmacometabolomics Enables Precision Medicine. Clinical Pharmacology \& Therapeutics 98(1): 71-75.

87. Kerssens Chantal, Renu Kumar, Anne E Adams, Camilla C Knott, Laura Matalenas, et al. (2015) Personalized Technology to Support Older Adults with and Without Cognitive Impairment Living at Home. American Journal of Alzheimer's Disease \& Other Dementias ${ }^{\circledR}$ 30(1): 85-97.

88. Klauschen Frederick, Michael Andreeff, Ulrich Keilholz, Manfred Dietel, Albrecht Stenzinger (2014) The Combinatorial Complexity of Cancer Precision Medicine. Oncoscience 1(7): 504-509.

89. Lambin Philippe, Jaap Zindler, Ben Vanneste, Lien van de Voorde, Maria Jacobs, et al. (2015) Modern Clinical Research: How Rapid Learning Health Care and Cohort Multiple Randomised Clinical Trials 
Complement Traditional Evidence Based Medicine. Acta Oncologica 54(9): 1289-1300.

90. Lochhead Paul, Andrew T Chan, Reiko Nishihara, Charles S Fuchs, Andrew H Beck, et al. (2015) Etiologic Field Effect: Reappraisal of the Field Effect Concept in Cancer Predisposition and Progression. Modern Pathology 28(1): 14-29.

91. Montine Thomas J, Kathleen S Montine (2015) Precision Medicine: Clarity for the Clinical and Biological Complexity of Alzheimer's and Parkinson's Diseases. The Journal of Experimental Medicine 212(5): 601-605.

92. Monsma David J, David M Cherba, Patrick J Richardson, Sean Vance, Sanjeet Rangarajan, et al. (2014) Using a Rhabdomyosarcoma PatientDerived Xenograft to Examine Precision Medicine Approaches and Model Acquired Resistance: Precision Medicine in Rhabdomyosarcoma. Pediatric Blood \& Cancer 61(9): 1570-1577.

93. Nielsen Søren Nors (2007) What has modern ecosystem theory to offer to cleaner production, industrial ecology and society? The views of an ecologist. Journal of Cleaner Production 15(17): 1639-1653.

94. O’Donnell, Peter H, Keith Danahey, Michael Jacobs, Nisha R Wadhwa, et al. (2014) Adoption of a Clinical Pharmacogenomics Implementation Program during Outpatient Care-Initial Results of the University of Chicago '1,200 Patients Project'. American Journal of Medical Genetics Part C: Seminars in Medical Genetics 166(1): 68-75.

95. Ortega Victor, Bleecker Eugene, Deborah Meyers (2015) Asthma Pharmacogenetics and the Development of Genetic Profiles for Personalized Medicine. Pharmacogenomics and Personalized Medicine 9-22.

96. Poldrack Russell A, Timothy O Laumann, Oluwasanmi Koyejo, Brenda Gregory, Ashleigh Hover, et al. (2015) Long-Term Neural and

\section{ISSN: 2574-1241}

DOI: 10.26717/BJSTR.2018.09.001766

Rodolfo Wadovski. Biomed J Sci \& Tech Res

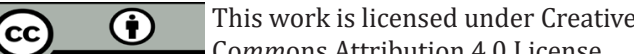

Submission Link: https://biomedres.us/submit-manuscript.php
Physiological Phenotyping of a Single Human. Nature Communications 6: 8885 .

97. Porter Michael E (1980) Competitive strategy: Techniques for analyzing industries and competition. New York, USA, pp. 300.

98. Preis Maren, Joerg Breitkreutz, Niklas Sandler (2015) Perspective: Concepts of Printing Technologies for Oral Film Formulations. International Journal of Pharmaceutics 494(2): 578-584.

99. Previati Maurizio, Marco Manfrini, Marco Galasso, Carlotta Zerbinati, Jeff Palatini, et al. (2013) Next Generation Analysis of Breast Cancer Genomes for Precision Medicine. Cancer Letters 339(1): 1-7.

100. Rodon J, JC Soria, R Berger, G Batist, A Tsimberidou, et al. (2015) Challenges in Initiating and Conducting Personalized Cancer Therapy Trials: Perspectives from WINTHER, a Worldwide Innovative Network (WIN) Consortium Trial. Annals of Oncology 26(8): 1791-1798.

101. Rubin EH, JD Allen, JA Nowak, SE Bates (2014) Developing Precision Medicine in a Global World. Clinical Cancer Research 20(6): 14191427.

102. Shah Rashmi R, Robert L Smith (2015) Addressing Phenoconversion: The Achilles' Heel of Personalized Medicine: Impact of Phenoconversion. British Journal of Clinical Pharmacology 79(2): 222-240.

103. The Precision Medicine Initiative Cohort Program (PMI) (2017) PMI Working Group Report to the Advisory Committee to the Director, NIH.

104. Thorogood Adrian, Yann Joly, Bartha Maria Knoppers, Tommy Nilsson, Peter Metrakos, et al. (2014) An Implementation Framework for the Feedback of Individual Research Results and Incidental Findings in Research. BMC Medical Ethics 15(1): 88.

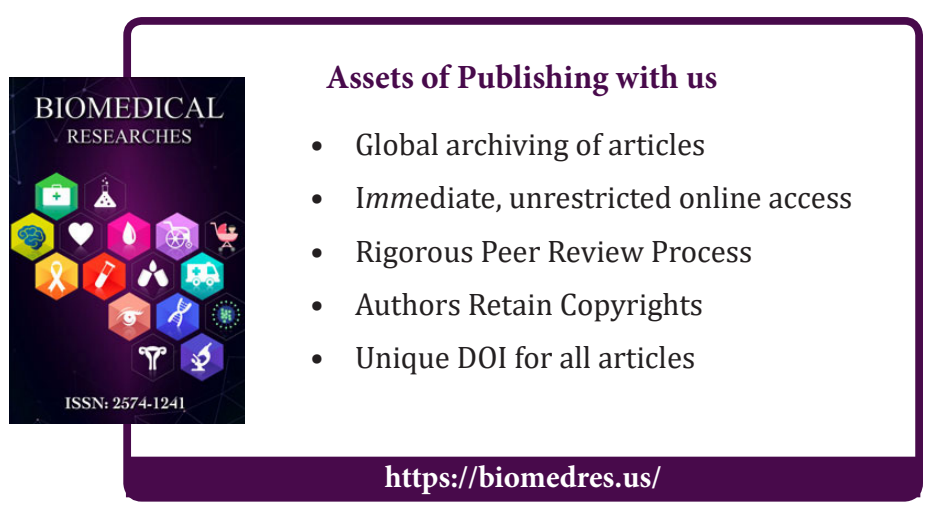

Cite this article: Rodolfo Wadovski, Roberto Nogueira, Paula Chimenti. Charting Ecosystems of Complex Phenomena: The Precision Medicine 